\title{
Protective Effects of Honey Solution and Fagonia indica Alcoholic Extract Against Ethanol-Induced Gastric Ulcer in Rats
}

Amina Mahdy ${ }^{{ }^{*}}$, Naglaa Gamil Shehab ${ }^{1}$ and Fathia Ali Bayoumi ${ }^{2}$

${ }^{1}$ Faculty of Pharmacy Cairo University, currently at Dubai Pharmacy College, Dubai, UAE

${ }^{2}$ Dubai Medical College for Girls, Dubai, UAE

\begin{abstract}
Background: Gastric ulcer is one of the most prevalent gastrointestinal diseases worldwide. Protection against peptic ulcer disease (PUD) was directed at using many natural products and medicinal plants extracts since it is believed that the natural remedies are giving good healing with little harm. The present study was undertaken to investigate the possible protective effect(s) of the alcoholic extract of Fagonia indica (Zygophyllaceae) in comparison to the documented beneficial effects of natural honey solution in a model of ethanol-induced gastric ulcer.
\end{abstract}

Methods: Albino rats were used in the study, divided into four groups from which one received only the vehicle (1\% CMC) and served as normal control. In the other three groups, fasting animals were subjected to induction of gastric ulcer by single ingestion of $80 \%$ ethanol solution, either alone or following oral treatment with either honey solution $(150 \mathrm{mg} / \mathrm{kg} /$ day) or Fagonia indica extract (20 mg/ $\mathrm{kg} /$ day) for two weeks. Macroscopic as well as microscopic examination were carried out and statistical significance between every two groups was checked by students-t test.

Results: These revealed a significant protection of Fagonia indica extract as compared to honey solution evidenced by producing marked lower ulcer index and ulcer score while producing higher preventive index ( $89 \%$ for the plant extract versus $69 \%$ for honey solution). On a microscopic level, both honey and Fagonia indica caused magnificent protection of the mucosa against the damage induced by ethanol resulting both in similar degrees of protection.

Conclusion: The wide usage of Fagonia indica extract in folk medicine is therefore encouraged since it is now demonstrated to possess a potent gastroprotective effect against ethanol-induced gastric ulcer. Combination of both the plant extract and honey can be advised since expected to produce more protection.

\section{Introduction}

Peptic ulcer disease (PUD) is one of the most prevalent gastrointestinal diseases affecting $5-10 \%$ of population worldwide $[1,2]$. Itis characterized by mucosal damage with inflammatory cell infiltration and coagulation necrosis [3]. PUD is a complex disease with multiple contributing factors and unclear etiology [4]. It is believed that PUD is mainly due to imbalance between aggressive and defensive factors affecting gastric mucosa leading to ulcerative damage [3,5]). Pepsin, $\mathrm{HCl}$, reactive free radicals, and refluxed bile are some of aggressive factors [6] while bicarbonate, mucus secretions, mucosal blood flow, nitric oxide (NO), prostaglandins (PGs) as well as enzymatic and non-enzymatic antioxidants are some of the defensive factors [6,7]. Several other factors contribute to the etiology of ulcer progression, for instance, Helicobacter pylori (H. pylori) infection, smoking, excessive use of non-steroidal anti-inflammatory drugs or alcohol, and psychological stress [8,9]. Excessive alcohol consumption apparently raise the risk for major upper gastrointestinal mucosal ulceration and bleeding.

Generally, management of peptic ulcer includes the use of drugs that inhibit gastric acid secretion and/or eradicate $H$. pylori [9]. However, efficacy of current therapy is not absolute and prolonged use is associated with side effects and ulcer relapse [10,11]. Medicines of plant origin are becoming increasingly favored since a natural substance is expected to promote healing and alleviate illness usually without significant adverse effects [12]. acid [19]. E-mail: amina@dpc.edu org/10.15344/2456-3501/2018/133

\section{Publication History:}

Received: December 23, 2017

Accepted: February 15, 2018

Published: February 17, 2018

Keywords:

Ethanol, Fagonia indica, Gastroprotective, Honey, PUD, Ulcer agentinmany experimental model of PUD $[13,14]$. Similarly, several medicinal plant extracts known for their antioxidant properties were widely investigated as gastroprotective agents $[15,16]$.

Fagoniaindica (family Zygophyllaceae) is a small green spiny under-shrub widely distributed in warm areas of Asia and Africa [17]. Traditionally, this plant has been employed for its anti-inflammatory, antipyretic and analgesic properties [18]. In an earlier study, the authors reported that the plant could be considered as safe and that it contained a variety of bioactive flavonoids, sterols and triterpenoids [19]. The plant is also rich in saponins, tanins and cardiac glycosides [20]. The alcoholic extract of the whole plant was found to exhibit antimicrobial, anti-tumor and analgesic activities. Most of its documented biological activities were found to be attributed mainly to saponin glycosides, triterpenoid saponins, flavonols and rosmarinic

"Corresponding Author: Prof. Amina Mahdy, Dubai Pharmacy College, P.O Box 19099, Muhaisna 1, Dubai, UAE. Tel: 971- 42120306, Fax: 971-42426704;

Citation: Mahdy A, Shehab NG, Bayoumi FA (2018) Protective Effects of Honey Solution and Fagonia indica Alcoholic Extract Against Ethanol-Induced Gastric Ulcer in Rats. Int J Clin Pharmacol Pharmacother 3: 133. doi: https://doi.

Copyright: (c) 2018 Mahdy, et al. This is an open-access article distributed under the terms of the Creative Commons Attribution License, which permits unrestricted use, distribution, and reproduction in any medium, provided the original author and source are credited. 
Citation: Mahdy A, Shehab NG, Bayoumi FA (2018) Protective Effects of Honey Solution and Fagonia indica Alcoholic Extract Against Ethanol-Induced Gastric Ulcer in Rats. Int J Clin Pharmacol Pharmacother 3: 133. doi: https://doi.org/10.15344/2456-3501/2018/133

Page 2 of 6

The objective of the present investigation was to re-assess, in an animal model, the gastroprotective effects of natural honey solution and to screen for possible protective effects of Fagonia indica alcoholic extract as a gastroprotective non-traditional remedy. Gastroprotective effects were assessed using ulcer index and calculated protective index as well as histopathological examination. Alcohol-induced gastric ulcer in rats was carried out as a model for mimicking the PUD in humans

\section{Material \& Methods}

\section{Fagonia indica alcoholic extract}

Whole plant was collected during September 2015 from Muhaisna 1 area, Dubai. The plant was kindly identified and authenticated by Prof. Hassnaa Ahmed Hosny, Department of Botany, Faculty of Science, Cairo University, Egypt. Voucher specimens were kept at the Herbarium of the Pharmacognosy Department, Faculty of Pharmacy, Cairo University and in Dubai Pharmacy College, Dubai. The plant was air-dried, powdered (500 g) and then macerated in $70 \%$ alcohol. After filtration, the filtrate was evaporated at $50^{\circ} \mathrm{C}$ using rotary evaporator and the residue $(75 \mathrm{~g})$ was collected for the biological study. Extract solution was freshly prepared by dissolving the residue in 1\% carboxymethylcellulose (CMC). Acute toxicity study of Fagonia indica alcoholic extract was previously investigated by the authors [19].

\section{Honey solution}

Pure, unprocessed, non-boiled commercial honey obtained from Faculty of Agriculture, Cairo, Egypt was used for this study. Honey was examined, chemically tested and found to be free from inverted sugar, liquid glucose or dextran. For experiments, fresh $10 \% \mathrm{w} / \mathrm{v}$ solution was prepared with distilled water.

\section{Animals \& Experimental Design}

Male Albino rats ( $n=40$ ), weighing between 220-250g, were obtained from the animal house facility of Dubai Pharmacy College and divided into 4 groups of ten animals each. They were housed under conditions of controlled temperature $\left(23 \pm 2^{\circ} \mathrm{C}\right)$ and illumination (12 hourslight/ dark cycle) one week prior to and throughout the experimentation period and had free access to water and food. One group was kept as normal without any treatment, while the other three groups were fasted for 28 hours (water was accessible except for the last 2 hours), then administered $80 \%$ ethanol solution $(0.5 \mathrm{ml}$ of ethanol per each $100 \mathrm{~g}$ animal body weight) either alone (control ulcer) or with previous treatment with either honey solution $(150 \mathrm{mg} / \mathrm{kg} /$ day) or Fagonia indica extract $(20 \mathrm{mg} / \mathrm{kg} /$ day $)$. Animals administered honey solution and the plant extract by oral gavage and continued for 14 days, the last dose being given $1 \mathrm{~h}$ before induction of ulcer with ethanol. The normal group received the vehicle $(1 \% \mathrm{CMC})$ similarly by oral gavage over the two weeks treatment period. All animals' investigations were performed in accordance with the ethical standards for the proper care and use of laboratory animals and upon approval of the Research Ethical Committee of Dubai Pharmacy College, Dubai, United Arab Emirates.

\section{Anti-ulcerogenic activity}

Rats were sacrificed under ether anesthesia 1 hour after ethanol administration. The stomach was removed and opened along the greater curvature, then rinsed with saline to remove blood clots and gastric contents before being fixed on cardboard to examine the gross gastric lesions. The gastric mucosal layer was carefully inspected using an illuminated magnifying lens for occurrence of ulcers which were measured for their individual lengths. Moreover, each stomach lesions were scored as follows: $0=$ Normal colored stomach, $0.5=$ Red coloration, $1=$ Spot ulcer, $1.5=$ Streaks $<3 \mathrm{~mm}$ length, $2=$ Streaks $\geq 3$ $\leq 5 \mathrm{~mm}$ length and finally, $3=$ Streaks $>5 \mathrm{~mm}$ length.

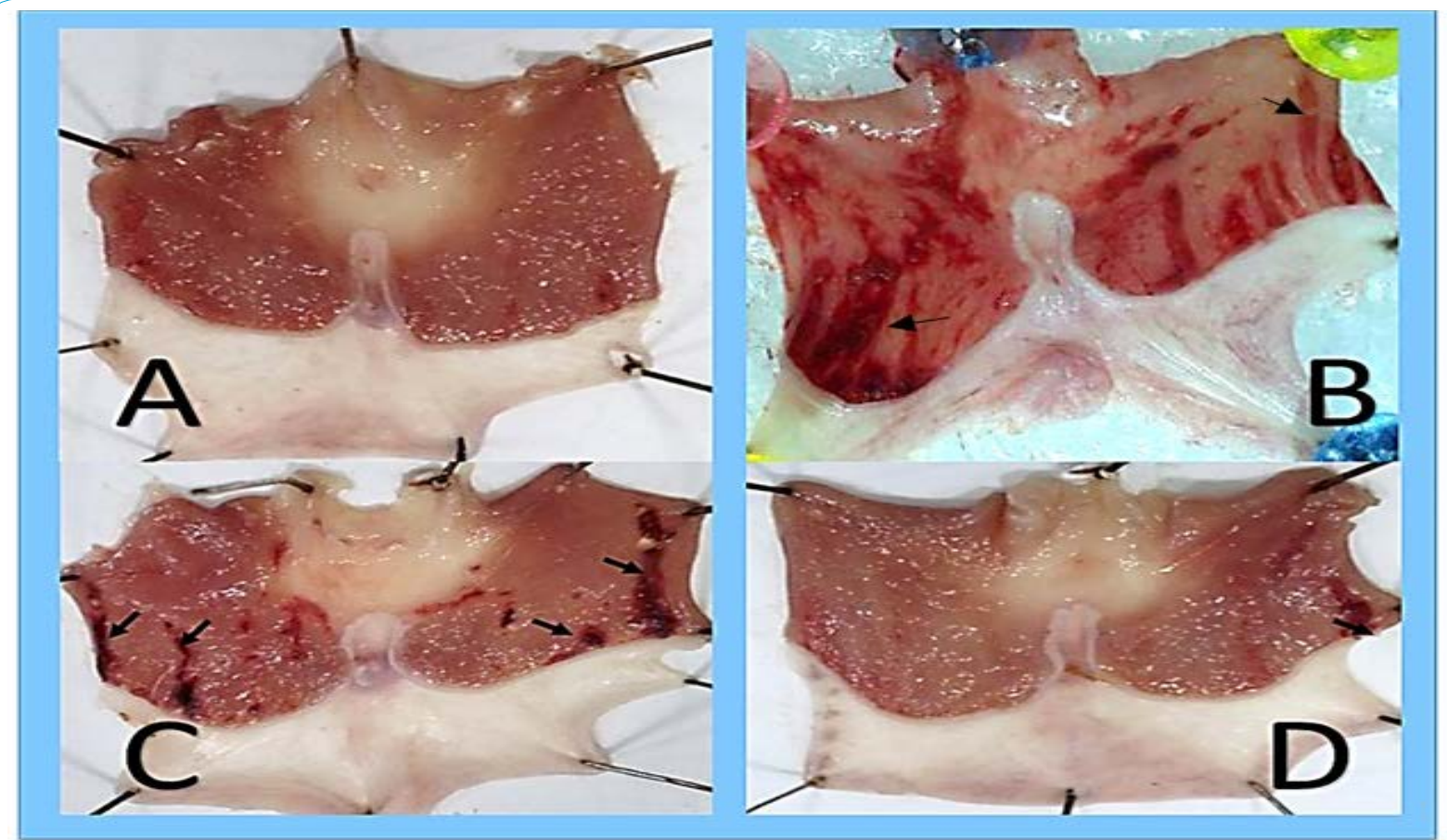

Figure 1:Effect of treatment with honey solution and Fagonia indica extract for 14 days on stomach lesions induced by $80 \%$ ethanol in fasting rats. A: normal stomach mucosa. B: untreated group receiving only ethanol. C: honey-treated group. D: Fagonia indica-treated group 
Citation: Mahdy A, Shehab NG, Bayoumi FA (2018) Protective Effects of Honey Solution and Fagonia indica Alcoholic Extract Against Ethanol-Induced Gastric Ulcer in Rats. Int J Clin Pharmacol Pharmacother 3: 133. doi: https://doi.org/10.15344/2456-3501/2018/133

Page 3 of 6

\section{Ulcer index, Ulcer Score, and Preventive Index}

According to [21], the sum of lengths of all lesions (in millimeters) in each stomach was regarded as the ulcer index (UI). The ulcer score (US) was calculated as the average score of ulcers/stomach in each group [22]. The preventive index of a drug is the percentage inhibition of gastric mucosal damage compared to control untreated results [23]. It is calculated according to the following formula

$$
P I \%=\left[\frac{\mathrm{UI}_{\text {ETOH }}-\mathrm{UI}_{\text {Treated }}}{\mathrm{UI}_{\text {ETOH }}}\right] \times 100
$$

\section{Histopathological study}

Stomach samples were fixed using $10 \%$ formaldehyde for histopathological examination. These tissues were processed and embedded in paraffin wax. Sections of $5 \mu \mathrm{m}$ in thickness were cut and stained with hematoxylin and eosin [24].

\section{Statistical analysis}

Data were collected using Microsoft Excel, analyzed using SPSS program (version 24) and presented as means + SEM. Comparison between means of each two groups was performed using student's t-test.

\section{Result}

In the present study, the ethanol-induced ulcer model in male albino rats was employed. Oral administration of $80 \%$ ethanol to fasting rats caused extensive ulcerations in the gastric mucosa as compared to stomach isolated from normal rats. This is evident by the macroscopic examination of ulceration (Figure 1A \& Figure 1B) and the ulcer index in this group was $161.64 \pm 14.40 \mathrm{~mm}$ as compared to $2.18 \pm 0.56 \mathrm{~mm}$ in the normal group not receiving ethanol (Figure 2). Moreover, the ulcer score, calculated by the scoring system described in the methodology, revealed a score as high as 46.5 for ethanoltreated rats while the normal rats score was 2 (Figure 2).

Treatment of rats for 14 days with either honey solution or Fagonia indica alcoholic extract was efficient in reducing gastric lesions in the tested doses as demonstrated by the sample pictures of gastric mucosa (Figure 1C \& Figure 1D). The treatment with both agents resulted in significantly lower ulcer indices compared to the untreated group $(49.47 \pm 3.21 \mathrm{~mm}$ and $18.22 \pm 1.66 \mathrm{~mm})$ for honey-treated and Fagonia indica-treated groups respectively (Figure 2). Gastric protection (calculated preventive index) by honey solution was up to $69 \%$ and was significantly greater with Fagonia indica to reach $89 \%$, as shown in the tabulated data of figure 2.

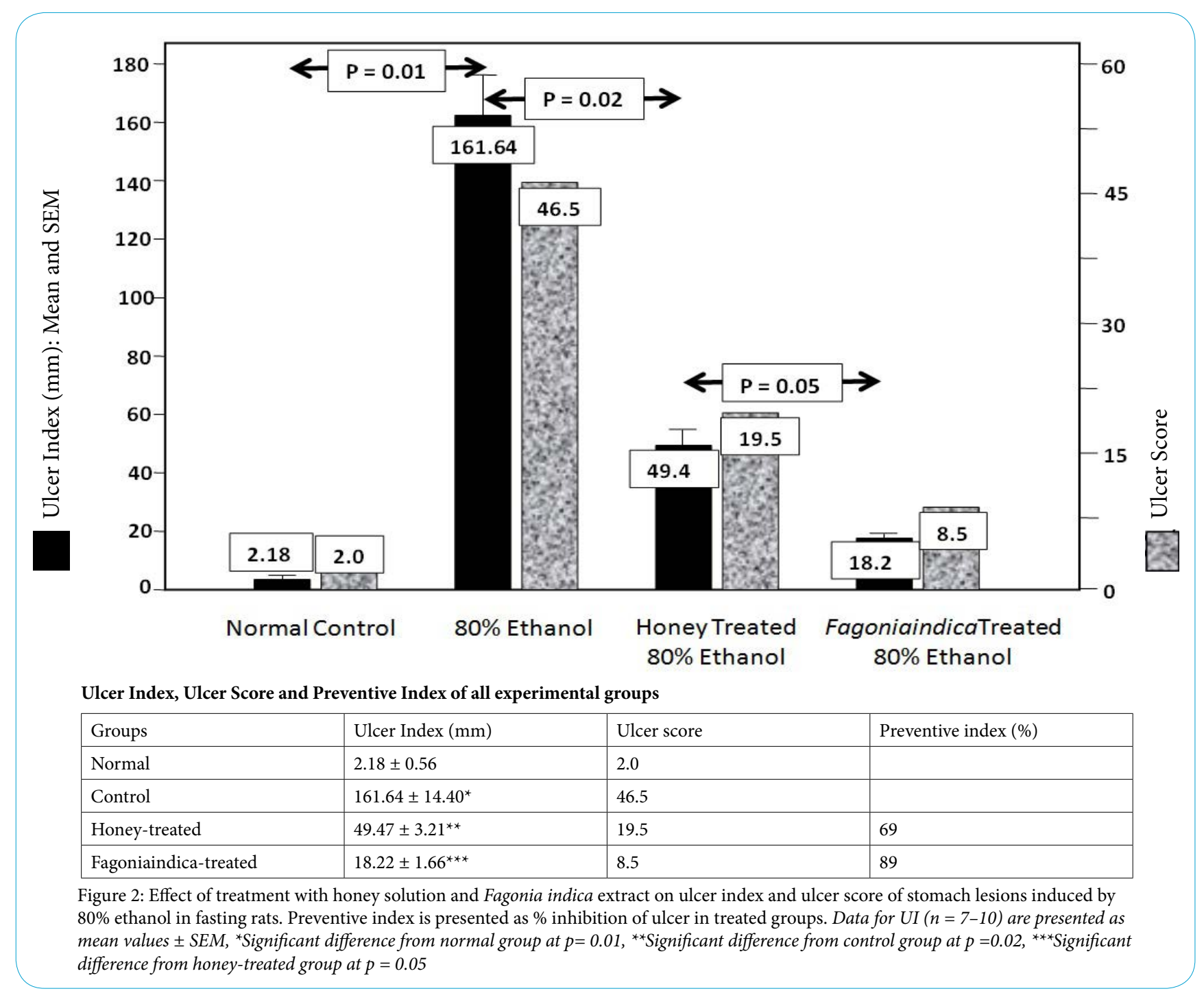


Citation: Mahdy A, Shehab NG, Bayoumi FA (2018) Protective Effects of Honey Solution and Fagonia indica Alcoholic Extract Against Ethanol-Induced Gastric Ulcer in Rats. Int J Clin Pharmacol Pharmacother 3: 133. doi: https://doi.org/10.15344/2456-3501/2018/133

Upon histopathological examination, sections taken from stomach of ethanol-treated animals showed marked hemorrhagic mucosal erosion and sloughing of necrotic cells. The lamina propria is edematous, congested and infiltrated by acute inflammatory cells together with mononuclear cells and hemosiderin-laden macrophages. Areas of hemorrhage are evident (Figure 3A \& Figure 3B). On the other hand, sections taken from stomach of honey-treated animals or Fagonia indica treated animals showed minimal focal erosions, mild inflammatory cellular infiltrate, markedly less congestion and edema as compared to ethanol-treated group (Figure 3C \& Figure 3D).

\section{Discussion}

Ethanol is known to damage the gastric mucosa by increasing leukocyte infiltration, decreasing mucosal blood flow and overproduction of free radicals [25]. The dissolution of bicarbonate and mucus by ethanol may also contribute to the deteriorating effect of ethanol [26]. Indeed, in an early study, administration of exogenous prostaglandins have been demonstrated to produce a dose-dependent protection against the gastric mucosal damage induced by alcohol in rats [27].

The assessment of the protective effects of both honey solution and Fagonia indica alcoholic extract, undertaken in the present study, was based on two main criteria; viz., macroscopic examination with the determination of ulcer index, ulcer score and protection index and microscopic examination of stomach specimens from different groups with identification of the histopathological findings.

The protective results obtained for honey solution in the present study against ethanol-induced lesions are in accordance with many

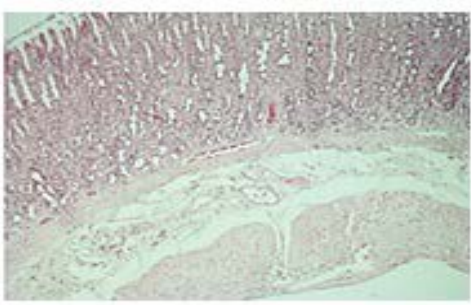

A) normal group receiving $1 \% \mathrm{CMC}$

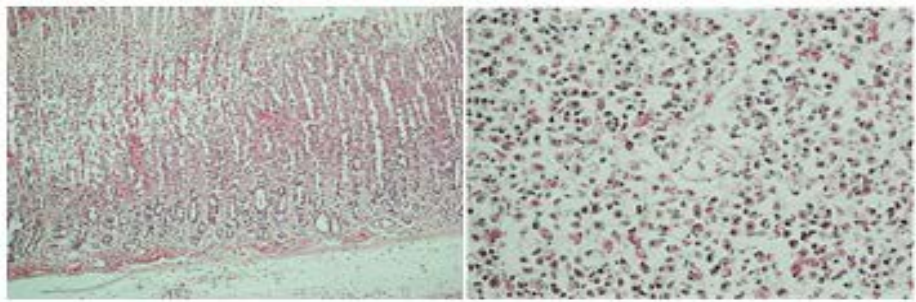

B) ulcer induced by ethanol $10 \times 20$ ulcer induced by ethanol 10x40

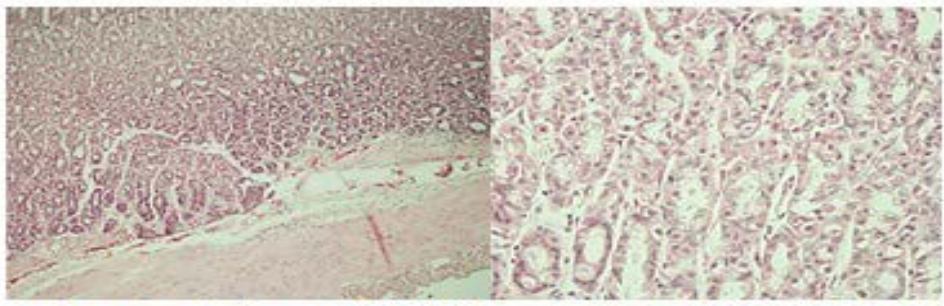

C)

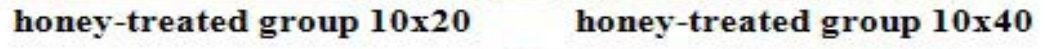

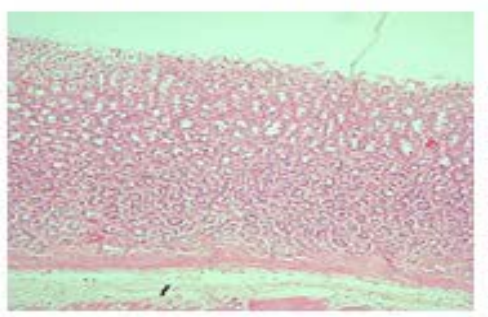

D) Fagonia-treated group $10 \times 20$

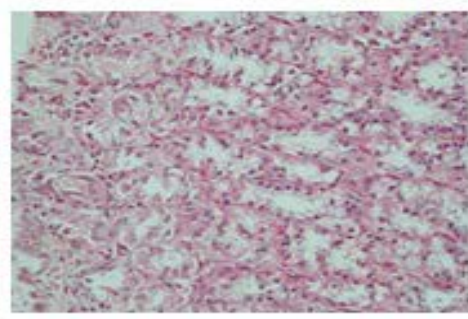

Fagonia-treated group $10 \times 40$

Figure 3: Histopathological findings of stomach sections from fasting rats; A) Normal animals which received only vehicle showing normal pattern. B) Animals ingested $80 \%$ ethanol without any treatment showing severe mucosal erosion and marked degree of inflammation with infiltrated cells. C) Rats treated with $20 \mathrm{mg} / \mathrm{kg} /$ day Fagonia indica extract for 14 days before ulcer induction and D) Rats treated with $150 \mathrm{mg} / / \mathrm{kg} /$ day bee honey $10 \%$ w $/ \mathrm{v}$ solution for 14 days before ulcer induction. Both C) and D) showed mild inflammatory cellular infiltrate with less congestion. 
Citation: Mahdy A, Shehab NG, Bayoumi FA (2018) Protective Effects of Honey Solution and Fagonia indica Alcoholic Extract Against Ethanol-Induced Gastric Ulcer in Rats. Int J Clin Pharmacol Pharmacother 3: 133. doi: https://doi.org/10.15344/2456-3501/2018/133

Page 5 of 6

previous researches which have demonstrated the gastroprotective activity of several types of honey, either unifloral or multifloral, and from different botanical origin $[28,29]$. It was demonstrated that honey has significant gastroprotective and antimicrobial properties including inhibition of the growth of $H$. pylori [13]. An investigation of antiulcer activity of honey in rats concluded that honey restored endogenous antioxidants, retarded lipid peroxidation and preserved mucus production levels through increased production of mucosal glycoproteins and preservation of the gastric mucosal glutathione [14].

The present investigation provides evidence that the alcoholic extract of Fagonia indica possesses a significantly marked degree of gastroprotection against ethanol-induced ulcer in rats. The protection potential of the plant extract was even greater than that of natural honey solution (as shown in the results section). Actually, the plant is widely used in folk and Ayurveda medicine as popular remedy for digestive disorders [30,31]. Since ethanol increases oxidative stress in gastric cells by the formation of free radicals and oxidation of polyunsaturated fatty acids, it is possible that the gastric protection effect of Fagonia indica is a result of its antioxidant effect. In fact, it was previously identified that the ethanolic extract of Fagonia indica contained a high concentration of polyphenolic compounds especially flavonoids from which quercetin was found to be a major [32]. Generally, polyphenolic compounds display a broad spectrum of physiological activities, hence, play a vital role in the prevention of various illnesses including certain kinds of cancer, diabetes, brain dysfunction or other conditions associated with the aging process as well as gastric ulcers [33]. The beneficial role of phenols in protection against mucosal damage was owed to that they stimulate PGE2 formation [34]. Other benefits are attributed to their antioxidant properties through their ability to scavenge free radicals, directly reducing peroxides, and stimulating the antioxidative defense enzyme activities [35]. Flavonoids are among the cytoprotective materials for which anti-ulcerogenic efficacy has been extensively confirmed $[36,37]$. Researchers demonstrated the protection of alcohol-induced gastric lesions by flavonoids especially quercetin, an element identified in Fagonia indica alcoholic extract $[38,39]$. Moreover, quercetin and its glycoside increased mucus production, an effect accompanied by a parallel reduction of gastric lesions [40].

\section{Conclusion}

In conclusion, the protective effect of honey solution is reconfirmed in ethanol-induced gastric ulcer in rats. On the other hand, the significant protective effect of Fagonia indica alcoholic extract is absolutely a new finding of this research work as it was not demonstrated before for this particular species to possess gastroprotective effect in such experimental model. Both honey and Fagonia indica exhibit their beneficial effects probably through antioxidant and mucus production mechanisms, owing to that they are both rich in flavonoids, thus falling in the category of cytoprotective agents. Compared to each other, the beneficial effect of Fagonia indica extract was proven to be significantly higher than that of honey solution as revealed by the gross examination parameters. On the other hand, on a microscopic level, the benefits of both honey solution and the plant extract were equivalent.

Further mechanistic studies are required to unveil molecular mechanism of gastric protection and isolate active constituents of Fagonia indica which might be specifically responsible for the protective action against mucosal damage.

\section{Competing Interests}

The authors declare that no competing interests exist.

\section{References}

1. Sung JJY, Kuipers EJ, El-Serag HB (2009) Systematic review: the global incidence and prevalence of peptic ulcer disease. Aliment Pharmacol Ther 29: $938-946$

2. Sumbul S, Ahmad MA, Mohd A, Mohd A (2011) Role of phenolic compounds in peptic ulcer: An overview. J Pharm Bioallied Sci 3: 361-367.

3. Halter F (1995) Pathophysiology of Peptic Ulcer Disease. In: Hollander D, Tytgat GNJ (Eds) Sucralfate: From Basic Science to the Bedside, Boston, MA: Springer, US 1-13.

4. Farzaei MH, Shams-Ardekani MR, Abbasabadi Z, Rahimi R (2013) Scientific evaluation of edible fruits and spices used for the treatment of peptic ulcer in traditional Iranian medicine. ISRN Gastroenterol 2013: 136932.

5. Tytgat GN (2011) Etiopathogenetic principles and peptic ulcer disease classification. Dig Dis 29: 454-458.

6. Repetto MG, Liesuy SF (2002) Antioxidant properties of natural compounds used in popular medicine for gastric ulcers. Braz J Med Biol Res 35: 523534.

7. Cryer B (2001) Mucosal defense and repair. Role of prostaglandins in the stomach and duodenum. Gastroenterol Clin North Am 30: 877-948.

8. Behrman SW (2005) Management of complicated peptic ulcer disease. Arch Surg 140: 201-208.

9. Ramakrishnan K, Salinas RC (2007) Peptic ulcer disease. Am Fam Physician 76: 1005-1012.

10. Bassi V, Fattoruso O, Polistina MT, Santinelli C (2014) Graves' disease shows a significant increase in the Helicobacter pylori recurrence. Clin Endocrinol 81: 784-795

11. Strand DS, Kim D, Peura DA (2017) 25 Years of Proton Pump Inhibitors: A Comprehensive Review. Gut Liver 11: 27-37.

12. Akhtar $\mathrm{AH}, \mathrm{Ahmad} \mathrm{KU}$ (1995) Anti-ulcerogenic evaluation of the methanolic extracts of some indigenous medicinal plants of Pakistan in aspirin ulcerated rats. J Ethnopharmacol 46: 1-6.

13. Bukhari MH, Khalil J, Qamar S, Qamar Z, Zahid M, et al. (2011) Comparative gastroprotective effects of natural honey, Nigella sativa and cimetidine against acetylsalicylic acid induced gastric ulcer in albino rats. $J$ Coll Physicians Surg Pak 21: 151-156.

14. Almasaudi SB, El-Shitany NA, Abbas AT, Abdel-dayem UA, Ali SS, et al (2016) Antioxidant, Anti-inflammatory, and Antiulcer Potential of Manuka Honey against Gastric Ulcer in Rats. Oxid Med Cell Longev 2016: 3643824.

15. Rozza AL, Pellizzon CH (2013) Essential oils from medicinal and aromatic plants: a review of the gastroprotective and ulcer-healing activities. Fundam Clin Pharmacol 27: 51-63.

16. Rtibi K, Jabri MA, Selmi S, Souli A, Sebai H, et al. (2015) Gastroprotective effect of carob (Ceratonia siliqua L.) against ethanol-induced oxidative stress in rat. BMC Complement Altern Med 15: 292-299.

17. Aggarwal BB, Prasad S, Reuter S, Kannappan R, Yadev VR, et al. (2011) Identification of novel anti-inflammatory agents from Ayurvedic medicine for prevention of chronic diseases: "reverse pharmacology" and "bedside to bench" approach. Curr Drug Targets 12: 1595-1653.

18. Waheed A, Barker J, Barton SJ, Owen CP, Ahmed S, et al. (2012) A novel steroidal saponin glycoside from Fagonia indica induces cell-selective apoptosis or necrosis in cancer cells. Eur J Pharm Sci 47: 464-473.

19. Shehab NG, Mahdy A, Khan SA, Noureddine SM (2011) Chemical constituents and biological activities of Fagonia indica Burm F. Res J Med Plants 5: 531-546.

20. Anil P, Nikhil B, Manoj G, Prakash NB (2012) Phytochemicals and biological activities of Fagoniaindica. Int Res J Pharm 3: 56-59.

21. Khattab MM, Gad MZ, Abdallah D (2001) Protective role of nitric oxide in indomethacin-induced gastric ulceration by a mechanism independent of gastric acid secretion. Pharmacol Res 43: 463-467. 
Citation: Mahdy A, Shehab NG, Bayoumi FA (2018) Protective Effects of Honey Solution and Fagonia indica Alcoholic Extract Against Ethanol-Induced Gastric Ulcer in Rats. Int J Clin Pharmacol Pharmacother 3: 133. doi: https://doi.org/10.15344/2456-3501/2018/133

22. Gupta JK, Upmanyu N, Patnaik AK, Mazumder PM (2010) Evaluation of antiulcer activity of Leucas Lavandulifolia on mucosal lesions in rats. Asian Journal of Pharmaceutical and Clinical Research 3: 118-120.

23. Nguelefack TB, Feumebo CB, Ateufack G, Watcho P, Tatsimo S, et al. (2008) Anti-ulcerogenic properties of the aqueous and methanol extracts from the leaves of Solanum torvum Swartz (Solanaceae) in rats. J Ethnopharmacol 119: 135-140.

24. Bancroft JD, Stevens A (1977) Theory and Practice of histological techniques. The Journal of the American Medical Association 238: 2730.

25. de-Faria FM, Almeida AC, Luiz-Ferreira A, Takayama C, Dunder RJ, et al (2012) Antioxidant action of mangrove polyphenols against gastric damage induced by absolute ethanol and ischemia-reperfusion in the rat. Scientific World Journal.

26. Choi EY, Hwang HJ, Kim IH, Nam TJ (2009) Protective effects of polysaccharide from Hizikia fusiformis against ethanol toxicity in rats. Food Chem Toxicol 47: 134-139.

27. Robert A, Nezamis J, Lancaster C, Hanchar A (1979) Cytoprotection by prostaglandins in rats. Prevention of gastric necrosis produced by alcohol, $\mathrm{HCl}, \mathrm{NaOH}$, hypertonic $\mathrm{NaCl}$, and thermal injury. Gastroenetrology 77: 433 443.

28. Gharzouli K, Amira S, Gharzouli A, Khennouf S (2002) Gastroprotective effects of honey and glucose-fructose-sucrosemaltose mixture against ethanol-, indomethacin-, and acidified aspirin-induced lesions in the rat. Experimental and Toxicologic Pathology 54: 217-221

29. Alagwu EA, Nneli RO, Egwurugwu JN, Osim EE (2011) Gastric cytoprotection and honey intake in albino rats. Nig J Physiol Sci 26: 39-42.

30. Chopra RM, Handa KL, Kapur LD, Chopra IC (1982) Indigenous Drugs of India. 2nd ed. New Delhi, India: Academic Press.
31. Chopra RM, Nayar SL, Chopra IC (1996) Glossary of Indian Medicinal Plants. 1st ed. New Delhi, India: National Insitute of Science Communication.

32. Shehab NG, Abu-Gharbieh E, Bayoumi FA (2015) Impact of phenolic composition on hepatoprotective and antioxidant effects of four desert medicinal plants. BMC Complement Altern Med 15: 401-412.

33. Scalbert A, lan T, Johnson IT, Saltmarsh M (2005) Polyphenols: Antioxidants and beyond. Am J Clin Nutr 81: 215S-217S.

34. Alanko J, Riutta A, Holm P, Mucha I, Vapata H, et al. (1999) Modulation of arachidonic acid metabolism by phenols: Relation to their structure and antioxidant/pro-oxidant properties. Free Radic Biol Med 26:193-201.

35. Cook NC, Samman S (1996) Flavonoids-Chemistry, metabolism, cardioprotective effects, and dietary sources. J Nutr Biochem 7: 66-74.

36. Di Carlo G, Mascolo N, Izzo AA, Capasso F (1999) Flavonoids: Old and new aspects of a class of natural therapeutic drugs. Life Sci 64: 337-353.

37. Borrelli F, Izzo AA (2000) The plant kingdom as a source of anti-ulcer remedies. Phytother Res 14: 581-591.

38. Martín MJ, La-Casa C, Alarcon-de-la-Lastra C, Cabeza J, Villegas I, et al. (1998) Antioxidant mechanisms involved in gastroprotective effects of quercetin. Z Naturforsch C 53: 82-88.

39. La Casa C, Villegas I, Alarcon De La Lastra C, Motilva V, Martin Calero MJ, et al. (2000) Evidence for protective and antioxidant properties of rutin, a natural flavone, against ethanol induced gastric Lesions. J Ethnopharmacol 71: $45-53$

40. Alarcón de la Lastra C, Martín MJ, Motilva V (1994) Antiulcer and gastroprotective effects of quercetin: a gross and histologic study. Pharmacology 48: 56-62. 